\title{
Energy efficiency and ecological quality of buildings by process control of heat supply systems
}

\author{
Andrey Benuzh", Sergey Fedorov and Ekaterina Orenburova \\ Moscow State University of Civil Engineering, Yaroslavskoe shosse, 26, Moscow, 129337, Russia
}

\begin{abstract}
The article presents special characteristics of mathematical modeling of the process control a resource efficient heat supply system of industrial buildings and facilities, where constant temperature maintenance is especially critical for the process. A functional diagram of the operation of the continuous heat supply process is provided. The dependence of temperature at the point of heat-transfer fluid mixing on environmental is analyzed and control system operation algorithm is proposed.
\end{abstract}

\section{Introduction}

Today the subject of energy efficiency has a great importance worldwide. Russian state program "Energy conservation and energy efficiency improvement for the period up to 2020" shows, that even government has its interest in high quality energy system. Moreover, the Paris Agreement has entered into force giving a boost to the transition towards a clean, smart, and secure energy infrastructure. In this context the issue of the enhancing the quality of the heat flow distribution in heat supply systems becomes significant as well. Improvement of heat flow control is an important problem of energy conservation to be considered in terms of impact on the environment.

\section{Scope of the work}

The heat balance in heating system pipelines was examined in the scientific works [1-4]. The formula (1) presents it for steel pipes:

$$
t_{A}=t_{\kappa}\left(1-e^{-\frac{\tau-\tau_{3}}{T}}\right)+t_{1} e^{-\frac{\tau-\tau_{3}}{T}}
$$

Where $t_{1}, t_{A}, t_{\kappa}$ - are the temperatures: of the heat-transfer fluid of the delivery pipeline, at point $\mathrm{A}$, and air in the heated space respectively ${ }^{o} \mathrm{C} ; \tau-$ the time, $\mathrm{s} ;{ }_{3}, T_{-}$ are the complete lag time in the transient process and the constant of heat load correspondingly, R, s.

\footnotetext{
* Corresponding author: ABenuzh@gmail.com
} 
The dependence is provided on Fig.1

$$
\hat{\gamma}_{\mathrm{H}}
$$

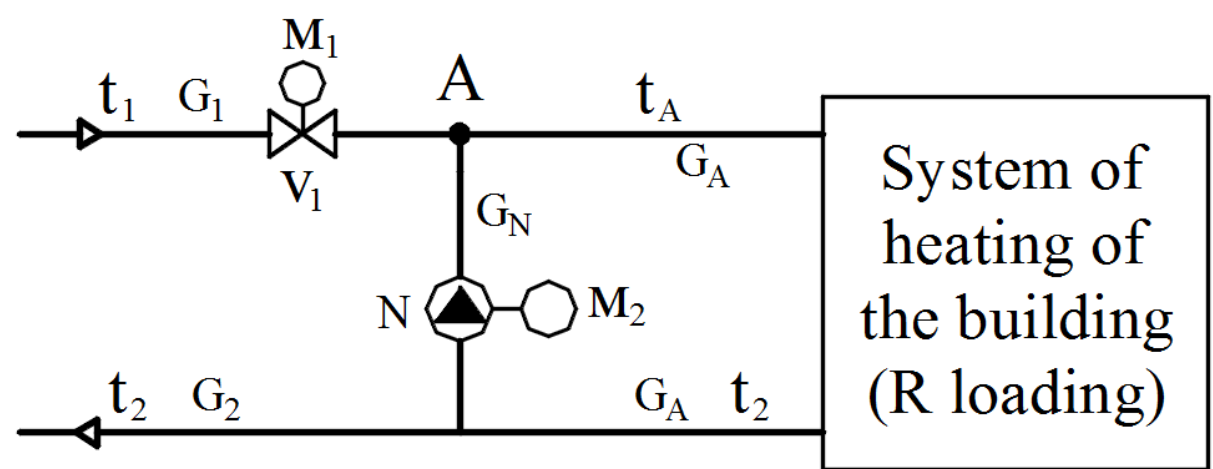

Fig. 1. Diagram of the dependent connection of a heating system with water mixing.

Expression (2) from (1) implies that:

$$
t_{\kappa}=\frac{t_{A}+t_{1} e^{-\frac{\tau-\tau_{3}}{T}}}{1-e^{-\frac{\tau-\tau_{3}}{T}}}
$$

\section{Methodology and discussion}

The expression does not include the value of external air temperature impact ${ }{ }_{H}$. This parameter is included in (2) to study the heat balance in such a scope. The correlation of $t_{H}, t_{A}, t_{\kappa}$ is provided below (3):

$$
t_{k}=\frac{t_{A}+\bar{k} \cdot t_{H}}{\bar{k}+1}
$$

Where $\bar{k}$ - is the dimensionless constant which includes heating system pipelines structure determined according to the equation (4):

$$
\bar{k}=\frac{k_{2} F}{k_{1} \pi d_{2} \ell}
$$

and (5):

$$
k_{1}=\frac{1}{\frac{1}{\alpha_{1}}+\frac{\delta_{m p}}{\lambda_{m p}}+\frac{1}{\alpha_{2}}},
$$

$\frac{1}{\alpha_{1}}, \frac{1}{\alpha_{2}}$ - are the heat resistances of heat interchange between the warm water in
Where
the pipeline and inner surface of the pipe wall and between the outer surface of the pipe 
wall and the air in the heated space $\mathrm{W} /\left(\mathrm{m}^{2}{ }^{\circ} \mathrm{C}\right) ;{ }^{\frac{\delta_{m p}}{\lambda_{m p}}}$ - is the heat resistance of the pipe wall, $\mathrm{W} /\left(\mathrm{m}^{2}{ }^{\circ} \mathrm{C}\right) ; d_{2}, \ell-$ are the outer diameter of the pipe and the length of the pipeline in the heating system, $\mathrm{m}$.

$$
k_{2}=\frac{1}{\frac{1}{\alpha_{3}}+\frac{\delta_{c m}}{\lambda_{c m}}+\frac{1}{\alpha_{4}}}
$$

Where $\frac{1}{\alpha_{3}}, \frac{1}{\alpha_{4}}$-are the heat resistances of heat interchange betwe
heated space and the inner surface of the building walls and roof,
surface of building walls and roof and the external air surrounding the
$\mathrm{F}$ - is the total area of the walls and roof, $\mathrm{m}^{2}$.
Comparing (2) and (3) we obtain the following expression:
\[ t_{A}=\frac{(\bar{k}+1) e^{-\frac{\tau-\tau_{3}}{T}} t_{1}+\left(e^{-\frac{\tau-\tau_{3}}{T}}-1\right) \bar{k} \cdot t_{H}}{\bar{k}+e^{-\frac{\tau-\tau_{3}}{T}}} \]

Let us put the expression (7) in the following form:

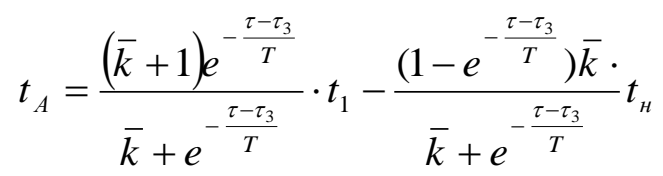

Let us obtain the dependence between the flow rates $G_{1}$ and $G_{N}$ of the delivery pipeline and the mixing pump correspondingly, using equation (8) and system (9):

$$
\left\{\begin{array}{l}
G_{A}=G_{1}+G_{N} \\
G_{A}\left(t_{A}-t_{2}\right)=G_{1}\left(t_{1}-t_{2}\right)
\end{array}\right.
$$

Having plugged (8) into (9) we obtain:

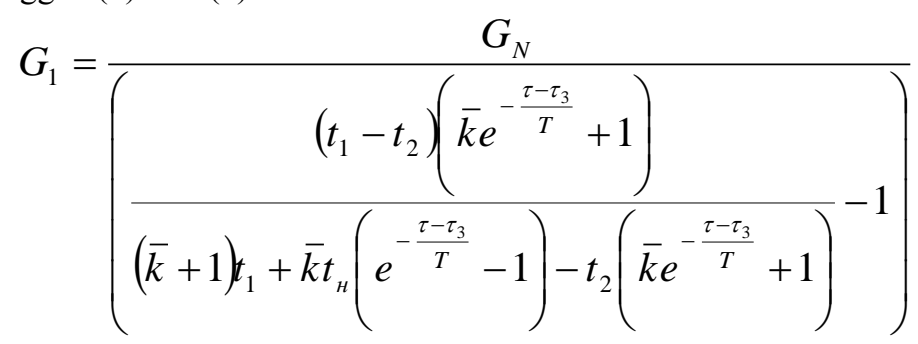


Expression (10) allows us to select some external air temperature $t_{H}$ as a control variable, and fluid flow rate $G_{1}$ in the delivery pipeline of the heating system as a controlled variable.

Using expressions (7) and (10) the control of the process of building heating in case of dependent connection to heat supply systems can be represented as a block diagram (Fig.2).

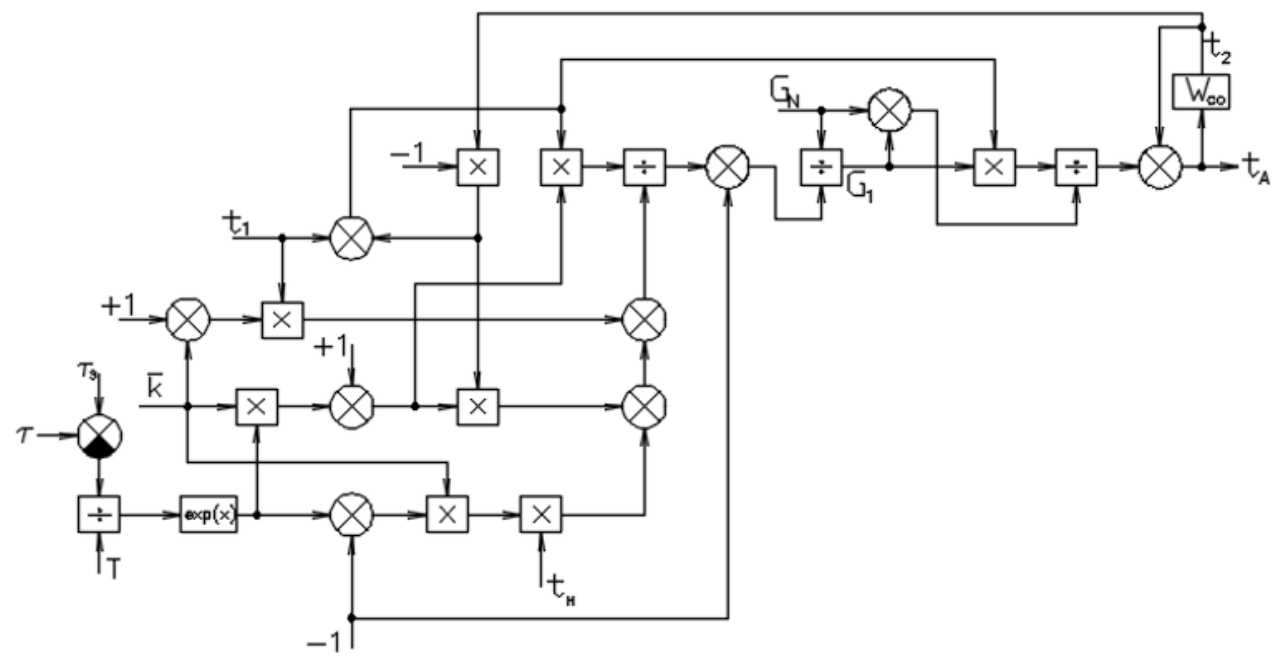

Fig. 2. Block diagram of continuous process control of building heat supply.

Based on the experimental information transient characteristics have the form of smooth curves [5]; the structure of the object of control in channel $t_{A}$ can be represented as a serious connection of a pure lag element and a first-order lag block, which is theoretically substantiated in (11):

$$
W_{c o}=\frac{k}{T S+1} \cdot e^{-S \tau_{3}}
$$

Where $\tau_{3}, T$ - are the pure lag time and the constant of a heating system, $\mathrm{s} ; \mathrm{k}-$ is the gain ratio; $\mathrm{S}-$ is the parametric variable.

However, regarding modern approach to the constriction and technology within the buildings with ecological aspects [6-8] even in that efficiency process control of heat supply systems above should be consider ecological quality of living environmental [9-10]. Therefore energy efficiency and ecological quality of buildings must also consider economics model and risk management [11-13]. For example, energy consumption data can help consumers change their behaviour and become more energy efficient. It is also useful for policy-makers to effectively target, monitor and evaluate their measures and actions.

\section{Conclusions}

1. The article presented developed mathematical model of heating systems control for dependent connection of the heat load to heating networks.

2. Fig. 2 demonstrates the heating process control block diagram for independent connection to heating networks in transient mode. 
3. Analyzing the obtained mathematical model basic control variable $t_{H}$ and basic controlled variable $t_{A}$ were found.

4. Increasing of the energy performance of buildings can have a positive impact, not only in economic terms, but also regarding public health and safety with indoor climate improving.

5. There is a need to improve the technical skill of the workers, dealing with energy systems equipment. The trainings are to provide the staff with the knowledge of the modern hardware and software and the key aspects of ecological issues of engineering systems of the buildings.

\section{References}

1. S.S. Fedorov, D.N. Tyutyunov, N.V. Klyueva. Constr. and Reconst. 5 (49), 36-39 (2013)

2. S.S. Fedorov, N.V. Klyueva, D.N. Tyutyunov Constr. and Reconst. 1 (51), 92-95 (2014)

3. N.V. Klyueva, V.I. Kolchunov, A.S. Bukhtiyarova Indust. and Civil Eng. 2, 37-41 (2014)

4. N.V. Klyueva, A.V. Malakhov, S.I. Gornostayev Constr. and Reconst. 5 (55), 23-28 (2014)

5. S.S. Fedorov, N.S. Kobelev, D.N. Tyutyunov, A.V. Boytsov, L.I. Studenikina, et al. News of Southwest st. Univ. 3 (48), 167-171 (2013)

6. A.A. Benuzh, E.N. Orenburova MATEC Web of Conferences 86, 05014, (2016)

7. A.A. Benuzh, E.N. Orenburova Hous. Constr. 2, 14-16 (2015)

8. V.I. Telichenko, A.A. Benuzh, G. Eames, E.N. Orenburova, N. Shushunova Procedia Engineering 153, 726-730 (2016)

9. V.I. Telichenko, A.A. Benuzh Indust. and Civil Eng. 10, 40-43 (2014)

10. R. Thakore, J. Goulding, A. Benuzh AEI 2013: Building Solutions for Architectural Engineering - Proceedings of the 2013 Architectural Engineering National Conference 877-890 (2013)

11. V.G. Borkovskaya, D. Passmore MATEC Web of Conference. (2018), International Scientific Conference Environmental Science for Construction Industry - ESCI 193, 193,05026 (2018)

12. V. Borkovskaya, E. Degaev, I. Burkova MATEC Web of Conference 2018, International Scientific Conference Environmental Science for Construction Industry - ESCI 193, 193,05027 (2018)

13. V.G. Borkovskaya W. Bardenwerper, R. Roe IOP Conf. Series: Materials Science and Engineering 365, 062030 (2018) 